\title{
A Century of Monitoring Urban Growth in Menofya Governorate, Egypt, Using Remote Sensing and Geographic Information Analysis
}

\author{
Islam Abou El-Magd1 ${ }^{*}$, Ahmed Hasan ${ }^{2}$, Abdelfatah El Sayed ${ }^{2}$ \\ ${ }^{1}$ Environmental Studies Department, National Authority for Remote Sensing and Space Sciences (NARSS), \\ Cairo, Egypt \\ ${ }^{2}$ Geography Department, Faculty of Social Sciences, Cairo University, Cairo, Egypt \\ Email: ${ }^{*}$ imagd@narss.sci.eg
}

Received 20 June 2015; accepted 14 August 2015; published 17 August 2015

Copyright $(\underset{2015}{ }$ by authors and Scientific Research Publishing Inc.

This work is licensed under the Creative Commons Attribution International License (CC BY). http://creativecommons.org/licenses/by/4.0/

(c) $\stackrel{\text { (i) }}{\mathrm{EY}}$ Open Access

\begin{abstract}
Urban growth is a global phenomenon mainly driven by the overpopulation growth particularly in developing countries like Egypt. Pattern and extent of urban growth could be monitored and modelled on a spatial and temporal dimension. GIS and remote sensing data along with other thematic maps were used to analyze the urban growth, pattern and extent in the last century in one of the biggest governorates at the heart of the Nile Delta of Egypt. Both spatial and temporal analyses enabled to identify the pattern of urban growth and subsequently project the nature of future growth. However, the overall urban growth in the last century was 12 times the original built up areas in 1910; the third stage from 1950 to 1972 was the highest stage of urban growth with 124\% increase of the built-up area. The dominant pattern of urban growth was linear along highways and railways with majority to the North, North East and North West directions. The study developed a spatial model to project urban growth by 2027 , indicating that urban growth in the Menofya Governorate would be continued at the same directions with the same pattern with an estimated increase of $33 \%$. The study provided an understanding of the controlling factors which drove the urban growth along this long time.
\end{abstract}

\section{Keywords}

Urban Growth, GIS, Remote Sensing, Modelling, Menofya Governorate, Egypt

\footnotetext{
${ }^{*}$ Corresponding author.
}

How to cite this paper: El-Magd, I.A., Hasan, A. and El Sayed, A. (2015) A Century of Monitoring Urban Growth in Menofya Governorate, Egypt, Using Remote Sensing and Geographic Information Analysis. Journal of Geographic Information System, 7, 402-414. http://dx.doi.org/10.4236/igis.2015.74032 


\section{Introduction}

Urban growth is a global phenomenon taking place in response to the population growth as well as economy and infrastructure initiatives. There is a clear difference between urban growth and sprawl, where the urban growth may have a planned appearance as a planned physical extension in response to the population growth; however the urban sprawl often appears awkward and uncontrolled [1]. In this context, the urban sprawl is defined as leapfrog of urban results from poorly planned, large scale residential, commercial and industrial in vacant land previously not used for urban purposes [2]-[4]. Indeed, unprecedented population growth coupled with unplanned developmental activities has led to urbanization, which takes place along roads and railways, or surrounding the city [5]. The extent of urbanisation always drives the change in land use patterns, which takes place in radial direction around the city centre or in linear direction along the highways [6]. In developing countries, it usually extends on the urban fringe, at the edge of an urban area or along the linear features such as roads, railways, and canals. Unfortunately, this phenomenon always poses serious implications on the resource base of the region.

Remote sensing technology provides a useful means for supplying up-to-date information on the activities within an urban environment that can be actively interfaced with geographic information systems for effective analysis that will best benefit planners [7] [8]. The built-up area is generally considered as the parameter for quantifying urban sprawl [9] [10]. It is quantified by delineating the impervious and existing built-up areas through the data acquired by remote sensing or thematic maps.

GIS is an effective tool in calculating the fragmentation of urbanized areas and landscape in terms of spatial changes [11]. Modelling the spatial and temporal dimensions has been an intense subject in studying geography [12]. It was efficiently used in determining the dynamics of land cover/land use change and urban growth [13]. GIS can be used for prediction and projection; it enables for modelling the spatial distribution of existing features, estimates the widest range of impacts of existing trends of population on urban sprawl [14] and detects patterns of urban sprawl [15]. The convergence of GIS and remote sensing with ancillary database is effective in quantifying, monitoring, modelling and subsequently predicting this phenomenon of urban sprawl [16]-[18].

This paper aimed at analyzing and understanding the pattern of urban growth and its dynamics in the last century and predicting the future population and urban growths.

\section{Study Area}

Menofya Governorate is located in the Nile Delta between Latitude $30^{\circ} 10^{\prime}$ and $30^{\circ} 45^{\prime} \mathrm{N}$ and Longitude $30^{\circ} 30^{\prime}$ and $31^{\circ} 15^{\prime}$ (Figure 1). Topographically, the governorate is generally flat with gentle general slope to the north. The climatic condition of the governorate is typical Mediterranean environment with hot summer with maximum temperature of $35^{\circ} \mathrm{C}$ in August and cold winter with minimum temperature of $18^{\circ} \mathrm{C}$ in January. The wind direction is normally from the North, North East and North West.

Menofya Governorate is very close to the capital Cairo, therefore its cities had long history of population and urbanization. The urbanization of the cities can be classified into three Eras a) old-Pharos Era 321-641, b) Arab Era 641-1798, and c) Modern Era 1798-2010. The old-Pharos Era inherited from Pharos Era, and most of the names are coming from this era such as Menouf that was named "Banouf Ris" and Tala that was called "Talanaou". However, the Arab Era they maintained the administrative boundaries and changes the Roman names to Arabic names and collectively gathered all these cities to Welayet Menofya (Menofya County). The last modern era, there was changing in the capital of the governorate from Menouf to Shebien El Koum, and increase in some details of the administrative structure and boundaries.

Table 1 lists the topographic maps sheets used to create the spatial database of the first 49 years (i.e. 1910-1950). The topographic maps were scanned using high resolution scanner with 600 DPI (Dot Per Inch) and registered to the source coordinate system. Secondly, the map sheets of the same stage (date) were mosaiced into a single sheet. Then, all mosaiced maps are transformed to the unified UTM grid system, zone 36N and Datum WGS 1984. Last, all built-up areas, and infrastructures were digitized on-screen. This enabled for getting 1910 , 1927 and 1950 datasets from these topographic maps. However, the last three dates $(1972,1998$ and 2010) were extracted from satellite images.

Table 2 lists the satellite sensors used to create the spatial extension of urban growth from 1972 to 2010. These images subjected to both pre and post processing. The image processing analyses used in this research in- 


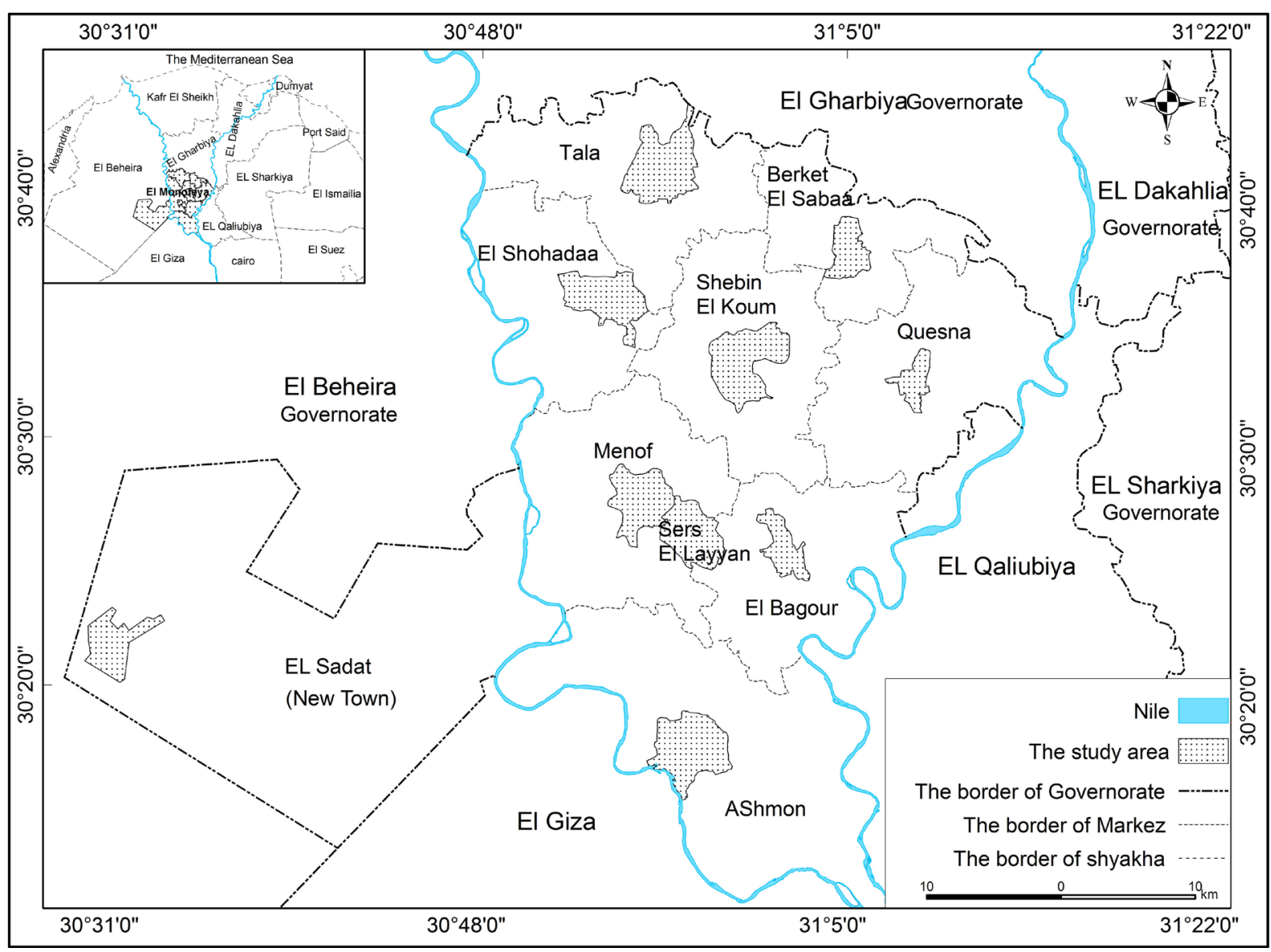

Figure 1. Location of the area of study.

Table 1. List of the topographic maps used in this study.

\begin{tabular}{ccccccc}
\hline$\#$ & Map & Date & \# of Sheets & Scale & Grid System & Source \\
\hline 1 & Topographic Maps & 1910 & 4 & $1: 50,000$ & $\begin{array}{c}\text { Geographic } \\
\text { (Lat./Long.) }\end{array}$ & $\begin{array}{c}\text { Center of Studies and Documentation } \\
\text { of Economic, Legal and Social }\end{array}$ \\
2 & Topographic Maps & 1927 & 11 & $1: 25,000$ & $\begin{array}{c}\text { Egyptian Transverse } \\
\text { Mercator } \\
\text { Geographic } \\
\text { (Lat./Long.) }\end{array}$ & Egyptian Survey Authority \\
\hline & Topographic Maps & 1950 & 4 & $1: 100,000$ & Egyptian Survey Authority \\
\hline
\end{tabular}

Table 2. List of the satellite images used in this study.

\begin{tabular}{cccccc}
\hline$\#$ & Sensor & Date & \# Channels & Path/Row & Pixel Size (m) \\
\hline 1 & MSS & 1972 & 4 & $190 / 39$ & $79 * 79$ \\
2 & TM & 1998 & 7 & $177 / 39$ & $30 * 30$ \\
3 & Egypt Sat1 & 2010 & 3 & - & $7.8 * 7.8$ \\
\hline
\end{tabular}

cluded bands extraction, restoration, enhancement, and classification. The maximum likelihood classifier (MLC) was employed for classification. The initial classification of land-use was 10 categories, which later aggregated to built-up areas, vegetation, barren lands, desert, roads and water features. The variable spatial resolution of the satellite images $80 \mathrm{~m}$ of MSS and $30 \mathrm{~m}$ of TM and $7.8 \mathrm{~m}$ of the Egyptsat-1 played not a significant role in the uncertainty of the classification. In 1972 there was no denser land use features to create more confusion in the 
signature or urban, the dominance of urban and agricultural made a clear distinguish between both classes, however the uncertainty reached $18 \%$ due to the large size of the pixel. Although in 1998 the spatial resolution of the TM was 30 meter, there was urban growth and large mixture of land use classes that made the uncertainty of the signature reached to $16 \%$. Finally the Egyptsat-1 satellite resolution is $7.8 \mathrm{~m}$ which provided much better discrimination of urbanized areas with little uncertainty of $8 \%$. In this kind of urban growth on such long history, such uncertainty is acceptable for the comparison between these stages.

\section{Results and Discussions}

\subsection{Dynamic Stages of Urban Growth}

This study monitored the urban growth in the last century which lead to different scales and magnitude of urban growth. The urbanized area of Menofya Governorate has been developed and increased from $2.63 \mathrm{Km}^{2}$ in 1910 to $33.9 \mathrm{Km}^{2}$ in 2010 , which has gone through different stages of growth. The lack of available data in a consistent time interval was the reason behind this classification.

1) Stage I (1910-1927)

This stage started with the early of the $20^{\text {th }}$ century and has shown the World War I. The urbanized area of this stage started with $2.63 \mathrm{Km}^{2}$ and by the end of this stage it was $5.55 \mathrm{Km}^{2}$, which means that the area was more than doubled. The actual area increase was $2.9 \mathrm{Km}^{2}$ in 17 years. The actual area increase was nearly $111 \%$ of total area with a yearly flat rate of $6.5 \%$ (Table 3 ). Indeed, there were some factors that influenced positively and negatively such urban growth, which includes the World War I and the economic deterioration accompanied to the war and the flourish of the development once again at the end of the $1930^{\text {th }}$.

However, the yearly rate of growth all over the governorate was $6.5 \%$; it was not the typical case in all the governorate cities (Figure 2). The rate of growth is different in each city, however in general there were three cities out of nine increased with more than $11 \%$ and up to $29 \%$ of urban growth, which are Shebin El-Koum, Menof, and Tala (Table 3). These three cities only contributed by $54 \%$ of the total urban growth in the governorate in this stage. However the rest of the cities, the 6 cities were growing by a percent that was less than $10 \%$ and all are contributed by $46 \%$ of the overall urban growth in this stage. There were some reasons behind this accelerated rate of urban growth, which includes the increased offers of national employment and recruitment in some of these cities and the development of the railway from Cairo to Alexandria that acted as a catalyst for the urban growth.

Table 3. Area of the Menofya Governorate cities and per cent of urban growth.

\begin{tabular}{|c|c|c|c|c|c|c|c|c|c|c|c|c|}
\hline \multirow{2}{*}{ City } & \multicolumn{6}{|c|}{ Area in $\mathbf{K m}^{2}$} & \multicolumn{6}{|c|}{$\%$ of Growth } \\
\hline & 1910 & 1927 & 1950 & 1972 & 1998 & 2010 & 1910 & 1927 & 1950 & 1972 & 1998 & 2010 \\
\hline Ashmon & 0.25 & 0.54 & 0.66 & 1.53 & 2.53 & 3.21 & $9.5 \%$ & $9.7 \%$ & $9.2 \%$ & $9.5 \%$ & $9.4 \%$ & $9.5 \%$ \\
\hline AlBagor & 0.13 & 0.23 & 0.26 & 0.73 & 1.54 & 2 & $4.9 \%$ & $4.1 \%$ & $3.6 \%$ & $4.5 \%$ & $5.7 \%$ & $5.9 \%$ \\
\hline Alshohada & 0.35 & 0.43 & 0.5 & 1.26 & 2.17 & 2.73 & $13.3 \%$ & $7.7 \%$ & $7.0 \%$ & $7.9 \%$ & $8.0 \%$ & $8.1 \%$ \\
\hline Berket Elsabae & 0.13 & 0.35 & 0.44 & 1.28 & 2.03 & 2.6 & $4.9 \%$ & $6.3 \%$ & $6.1 \%$ & $8.0 \%$ & $7.5 \%$ & $7.7 \%$ \\
\hline Tala & 0.32 & 0.66 & 0.8 & 1.53 & 2.59 & 3.18 & $12.2 \%$ & $11.9 \%$ & $11.1 \%$ & $9.5 \%$ & $9.6 \%$ & $9.4 \%$ \\
\hline Sers Allyan & 0.35 & 0.51 & 0.63 & 1.27 & 2.15 & 2.85 & $13.3 \%$ & $9.2 \%$ & $8.8 \%$ & $7.9 \%$ & $8.0 \%$ & $8.4 \%$ \\
\hline Shebin El-Koum & 0.6 & 1.6 & 2.35 & 5.04 & 8.18 & 9.88 & $22.8 \%$ & $28.8 \%$ & $32.7 \%$ & $31.4 \%$ & $30.3 \%$ & $29.2 \%$ \\
\hline Qewisna & 0.04 & 0.52 & 0.66 & 1.41 & 2.48 & 3.21 & $1.5 \%$ & $9.4 \%$ & $9.2 \%$ & $8.8 \%$ & $9.2 \%$ & $9.5 \%$ \\
\hline Menof & 0.46 & 0.71 & 0.88 & 2 & 3.35 & 4.22 & $17.5 \%$ & $12.8 \%$ & $12.3 \%$ & $12.5 \%$ & $12.4 \%$ & $12.5 \%$ \\
\hline Total & 2.63 & 5.55 & 7.18 & 16.05 & 27.02 & 33.88 & $100.0 \%$ & $100.0 \%$ & $100.0 \%$ & $100.0 \%$ & $100.0 \%$ & $100.0 \%$ \\
\hline $\begin{array}{l}\text { Area of urban } \\
\text { increase }\left(\mathrm{km}^{2}\right)\end{array}$ & & 2.9 & 1.6 & 8.9 & 11.0 & 6.9 & & & & & & \\
\hline$\%$ of Total growth & & 111 & 29 & 124 & 68 & 25 & & $54 \%$ & $56 \%$ & $44 \%$ & $43 \%$ & $42 \%$ \\
\hline Stage Duration & & 17 & 23 & 22 & 26 & 12 & \multicolumn{6}{|c|}{$\begin{array}{l}\text { Cities with High Rate and Total Contribution } \\
\text { to the Overall All Urban Increase }\end{array}$} \\
\hline Yearly \% & & 6.5 & 1.3 & 5.6 & 2.6 & 2.1 & & & & & & \\
\hline
\end{tabular}




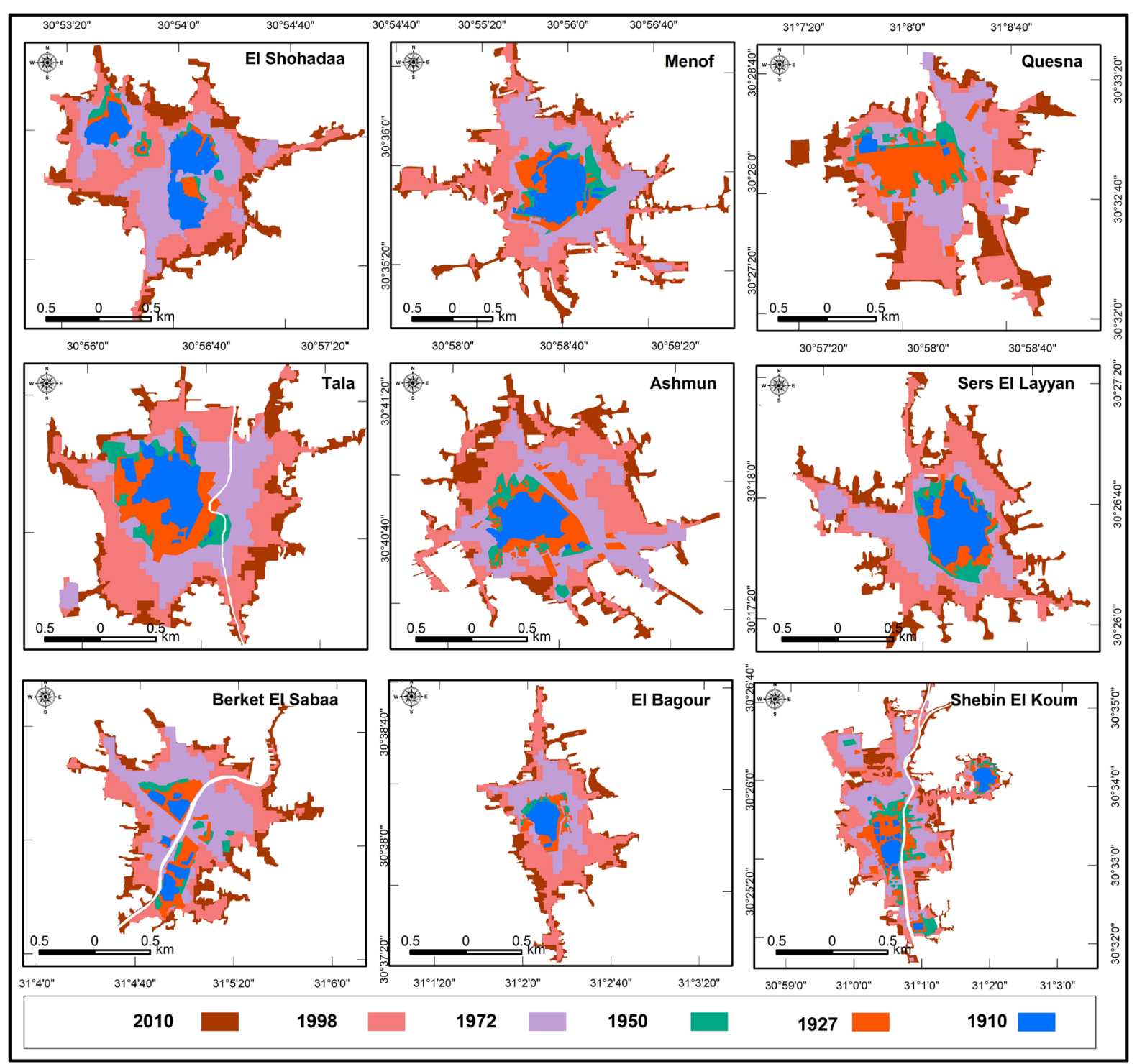

Figure 2. Urban growth in Menofya governorate cities from 1910 to 2010.

\section{2) Stage II (1927-1950)}

The second stage was from 1927 to 1950 for about 23 years long, which described as a slow motion stage of urban growth. This is due to the yearly rate of urban development was the least one of $1 \%$. This stage started after the World War I and ended with the World War II. The urbanized area started at $5.55 \mathrm{Km}^{2}$ and by the end of this stage it was $7.18 \mathrm{Km}^{2}$, which means that only $1.3 \mathrm{Km}^{2}$ is added within 23 years (Table 3). The actual area increase represents nearly $23 \%$ of total area with a yearly flat rate of $1 \%$. This stage went through some factors that influenced such slow urban growth; first it started after the World War I and the economic deterioration resulted from the War. Then, some economic flourish happened in the $1930^{\text {th }}$ that enabled for little urban development. Last, the World War II that probably had influence on the economical conditions and therefore the slow rate of urban growth.

However, the yearly rate of growth all over the governorate was $1.3 \%$; it was not the typical case in all the governorate cities. The rate of growth was different in each city, generally the same three cities of stage I, Shebin El-Koum, Meouf, and Tala, maintained the higher rate of urban growth from $11 \%$ and up to $33 \%$ (Table 3). These three cities only contributed by $56 \%$ of the total urban growth in the governorate in this stage. However the rest of the cities, the 6 cities were growing by a percent that was less than $10 \%$ and all were contributing by 
just $44 \%$ of the overall urban growth in this stage. The main reason behind the slow rate of urban growth was the economical situation due to the World War and the political conditions in Egypt.

\section{3) Stage III (1950-1972)}

The third stage was from 1950 to 1972 for about 22 years long, which described as fastest stage of urban growth. This is due to the area of urban development was more than doubled. The urbanized area of this stage started at $7.18 \mathrm{Km}^{2}$ and by the end of this stage it was $16.05 \mathrm{Km}^{2}$, which means that $8.9 \mathrm{Km}^{2}$ was added within 22 years. The actual area increase was nearly $124 \%$ of the total area with a yearly flat rate of $5.6 \%$ (Table 3 ). However, this stage went through different conditions, of World War II, the 1952 revolution and then the War with Israel but the population growth and local development influenced the high rate of urban growth in this stage.

This stage was the fastest stage of urban growth that reached $124 \%$ of the total urban growth. This rate was not consistent in all the government cities. Shebin El-Koum maintained the highest rate of $31 \%$ followed by Meouf at $12.5 \%$. These two cities only were contributing by about $44 \%$ of the total urban increase in the governorate in this stage. The other cities ranged from $4.5 \%$ to $9.5 \%$ with collective contribution by $56 \%$ of the whole governorate increase.

The reasons behind the high rate of urban growth were the population growth and the industrial development that accompanied the revolution of 1952 as well as the development of Cairo-Alexandria desert road.

\section{4) Stage IV (1972-1998) Speedy Stage}

The fourth stage was from 1972 to 1998 for about 26 years long, which described as balanced stage of urban growth. This is due to the area of urban development was nearly two third. The urbanized area of this stage started at $16.05 \mathrm{Km}^{2}$ and by the end of this stage it was $27.02 \mathrm{Km}^{2}$, which means that $11 \mathrm{~km}^{2}$ was added within 26 years. The actual area increase was nearly $68 \%$ of the total area with a yearly flat rate of $2.6 \%$ (Table 3 ). This stage was a continual of the third stage of fast development; however it started with the 1973 War that stopped the urban growth. The economical growth in the late 1970s and 1980s has influenced the urban growth and accelerated the rate of increase. By the end of this stage and the recognition from the government that the urban growth is negatively impacting the fertile agriculture land, a new policy and legislation introduced to protect the agricultural land from urban growth.

This stage was continual of the previous fasting stage of urban growth that reached an overall growth of $68 \%$. This rate was not consistent in all the cities, Shebin El-Koum maintained the highest rate of $30 \%$ followed by Menof at $12 \%$ (Table 3 ). These two cities only were contributing by about $43 \%$ of the total urban increase in the governorate in this stage. The other cities ranged from $6 \%$ to $10 \%$ with collective contribution by $57 \%$ of the whole governorate increase.

Indeed, the 1973 war with Israel has stopped the urban growth, the open economical period in the late 70s and 80s has flourished the urban growth again and enabled for a continual stage of high growth. At this time, the market of property and the price of land have increased dramatically that made pressure on urban growth for economical gain. This is why the government realized this issue and recognized the negative impact of urban growth on the fertile agriculture land and introduced the new legislation known as the military law, this was under the decree number 116/1983 that quoted "any person will develop urban on agriculture land will be subjected to courtesy with jail of at least 1 month and penalty between $50 \mathrm{k}-100 \mathrm{k}$ Egyptian Pound". This law is aiming at introducing the people of real case of urban growth on the agriculture land to the military court not civilian. This was to put pressure on the civilian people for not breaking the rules and stop urban growth over the agriculture land.

\section{5) Stage V (1998-2010) Cancer Stage}

The fifth stage was from 1998 to 2010 for about 12 years long, which witnessed for continual of urban growth. The urbanized area of this stage started at $27.02 \mathrm{Km}^{2}$ and by the end of this stage it was $33.88 \mathrm{Km}^{2}$, which means that $6.9 \mathrm{Km}^{2}$ was added within 12 years. The actual area increase was nearly $25 \%$ of total area with a yearly flat rate of $2.1 \%$. This stage also continued with fast urban growth; however the new legislation of execution and huge penalty was key factor for minimizing the rate of urban growth.

The last stage was also continual of the urban growth from the previous two stages, which reached an overall growth of 25\%. This rate was not consistent in all the cities; Shebin El-Koum maintained the highest rate of 29\% followed by Meouf at $12.5 \%$. These two cities only were contributing by about $42 \%$ of the total urban increase in the governorate in this stage. The other cities ranged from $6 \%$ to $9.5 \%$ with collective contribution by $58 \%$ of the whole governorate increase. 
The global economical crisis and the fall down of the global market of property have made the growth in this stage not at maximum as was anticipated. However, it continued to increase at $2.1 \%$ of annual increase.

Figure 3 shows the individual increase of built-up area in the nine cities of Menofya Governorate in the last century. It shows that the second half of the $20^{\text {th }}$ century experienced high rate of urban growth. Table 4 shows the number of times of urban growth; the area is doubled from 1910 to 1927; however it increased 2.7 times up to the half of the century (1950). From 1950 there was unprecedented increase, where the built-up area and urban growth were reached 10 times the base urbanized area of 1910. In total the urban cities were increased 12 times its initial area of 1910 .

\subsection{Direction and Pattern of Urban Growth}

Urban growth in Menofya Cities took place in radial and linear directions along the fringes of the cities. The pattern of urban growth is, however, complex due to preclusions of the existing land use and land cover. The occurrence of infrastructures such as highways or railways was acted as catalysts for the urban growth in Menofya cities. Figure 4 shows the pattern and direction of the urban growth in the last century of the nine cities, which shows that each city has had its own characteristics and influencing factors for urban growth in one direction or hindering the urban growth in other direction. Table 4 shows the percent of the urban growth in each di-

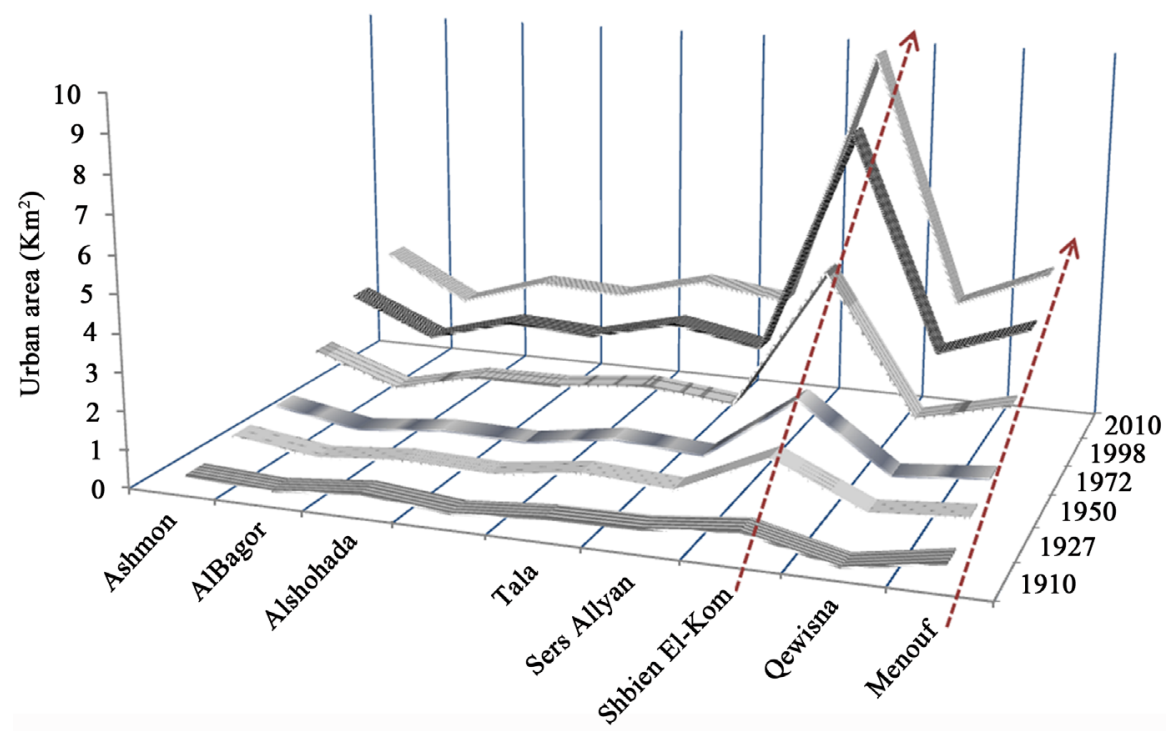

Figure 3. Comparative urban growth of each city from 1910 to 2010.

Table 4. Cumulative total urban growth of the Menofya governorate cities.

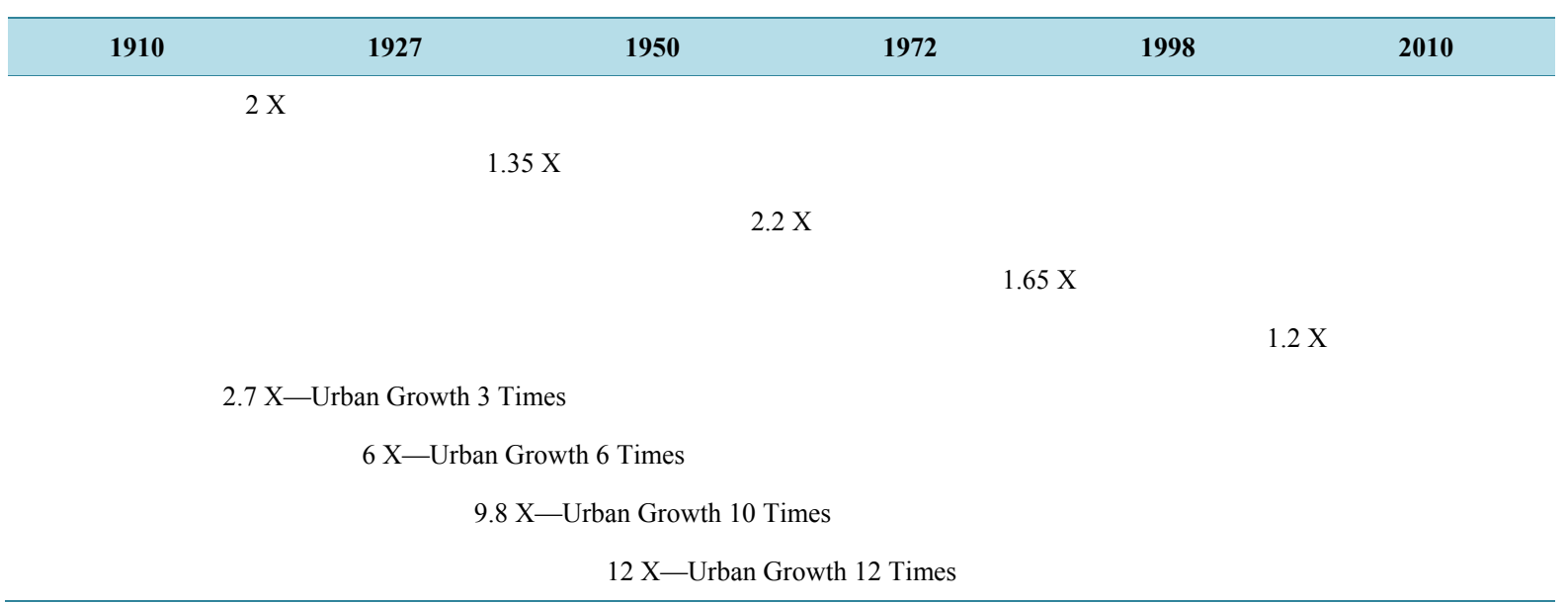




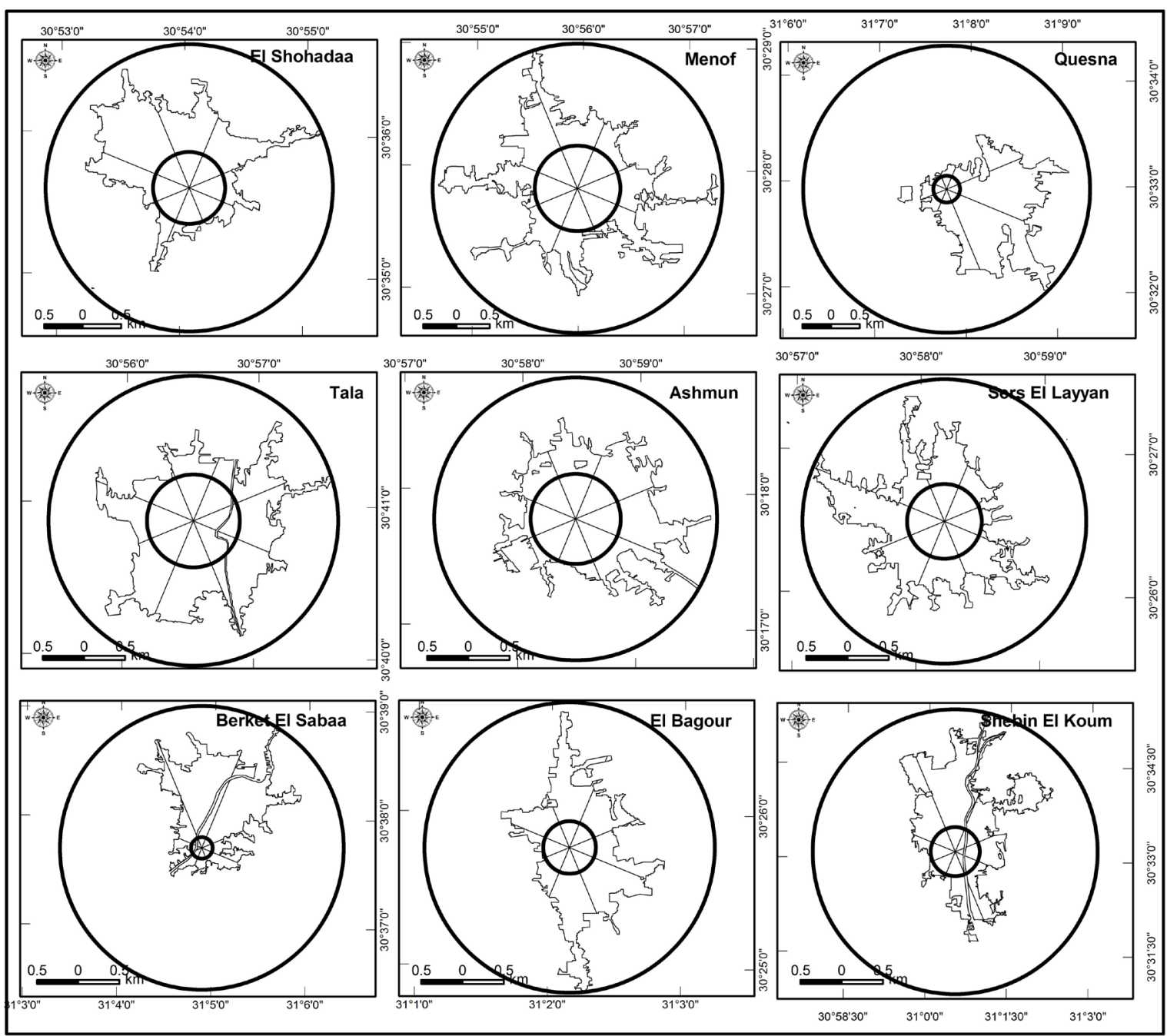

Figure 4. Direction of the urban growth in Menofya governorate cities from 1910 to 2010.

rection. The dominant directions were North, North East and North West; the growth in these directions was influenced by the wind direction for health issues. Besides the physical factors of the highways, railways and other infrastructures that accelerated the growth in these directions. However the linear pattern was the dominant patterns that was influenced by the linear infrastructures; there was some radial pattern in few cities such as Tala and Ashmoun (Figure 4).

Table 5 shows the average area and length of urban growth in each direction for the 9 cities of the Menofya governorate. It clearly shows that the northern direction has the highest value of $20 \%$ increase followed by north east, south east and east direction for $16 \%, 14 \%$ and $13 \%$ respectively. The other direction has shown urban growth but not at the same magnitude. In terms of the length of the urban growth in each direction, the south east direction has had the longest urban growth for $11 \mathrm{~km}$ that represents $15 \%$, followed by East, North West and North for 14\%, 14\% and 13\% respectively. However, the total area of urban growth in the north direction was the highest; it was not the lengthiest growth. This means that the urban growth in this direction is not only influenced by the linear features.

The lowest directions were mainly influenced by the existence of cemeteries, landfills and drainages that always disable further development and urban growth.

\section{Projection of Urban Growth}

To project the urban growth there is a need to understand the historical record of the population growth rate in 
Table 5. The area and length of urban growth in each direction from 1910 to 2010.

\begin{tabular}{cccccccccccccc}
\hline & \multicolumn{9}{c}{ Area $\left(\mathbf{K m}^{2}\right)$} & \multicolumn{7}{c}{ Length (Km) } \\
\hline Direction & $\mathbf{1 9 1 0}$ & $\%$ & $\mathbf{2 0 1 0}$ & $\mathbf{\%}$ & $\mathbf{1 9 1 0 - 2 0 1 0}$ & $\%$ & $\mathbf{1 9 1 0}$ & $\%$ & $\mathbf{2 0 1 0}$ & $\%$ & $\mathbf{1 9 1 0 - 2 0 1 0}$ & $\%$ \\
\hline North & 0.55 & $21 \%$ & 6.79 & $20 \%$ & 6.24 & $20 \%$ & 5.3 & $17 \%$ & 15.8 & $14 \%$ & 10.5 & $13 \%$ \\
North East & 0.49 & $18 \%$ & 5.45 & $16 \%$ & 4.96 & $16 \%$ & 5.4 & $18 \%$ & 15.2 & $14 \%$ & 9.8 & $12 \%$ \\
North West & 0.43 & $16 \%$ & 4.48 & $13 \%$ & 4.05 & $13 \%$ & 4.4 & $14 \%$ & 15.2 & $14 \%$ & 10.8 & $14 \%$ \\
East & 0.21 & $8 \%$ & 4.15 & $12 \%$ & 3.94 & $13 \%$ & 3.1 & $10 \%$ & 14 & $13 \%$ & 10.9 & $14 \%$ \\
West & 0.22 & $8 \%$ & 2.81 & $8 \%$ & 2.59 & $8 \%$ & 2.7 & $9 \%$ & 11 & $10 \%$ & 8.3 & $10 \%$ \\
South & 0.28 & $11 \%$ & 3.38 & $10 \%$ & 3.10 & $10 \%$ & 4.1 & $13 \%$ & 13.4 & $12 \%$ & 9.3 & $12 \%$ \\
South East & 0.23 & $9 \%$ & 4.54 & $13 \%$ & 4.31 & $14 \%$ & 3.2 & $10 \%$ & 14.7 & $13 \%$ & 11.5 & $15 \%$ \\
South West & 0.24 & $9 \%$ & 2.37 & $7 \%$ & 2.13 & $7 \%$ & 2.4 & $8 \%$ & 10.6 & $10 \%$ & 8.2 & $10 \%$ \\
Total & 2.66 & 1 & 33.97 & 1 & 31.32 & 1.00 & 30.60 & 1 & 109.90 & 1 & 79.30 & 1 \\
\hline
\end{tabular}

the nine cities of Menofya Governorate. Table 5 shows the population of these cities from 1907 till 2006. It shows the over increase of the population in the last century. Within this time frame the population started to increase by about $28 \%$ from 1910 to 1960 ; which then increased to the maximum of $36 \%$ in the period from 1960 to 1986 . In the last two decades, it started to gently decrease to about $20 \%$. Indeed, such population growth will inspire urban growth. Assuming the same rate of population increase, it is projected that the total population in the nine cities of the Governorate in 2027 will be 851,372 (Table 6). Therefore, this will put pressure on the urban growth for housing to accommodate such population growth.

GIS was used to simulate and project the urban growth within these cities up to 2027 (the date of the national development plan) that could accommodate the population growth. The projections of urban growth in Menofya governorate cities were basically analyzed based on the pixel diffusion according to the following equation and using specific weighting coefficients (Table 7). In this model four main parameters were used with the proposed projection coefficients, including the historical base of urban growth in the last 100 years, the population growth and the projected population growth, the directional growth that is broken down to the eight directions and the accelerating or hindering infrastructures that is broken down to roads, railways canals and drainages.

$$
U G=\sum_{x_{1} y_{1}}^{x_{n} y_{n}}\left(U_{c 1}+D_{c 2}+P P_{c 3}+A H_{c 4}\right)
$$

where:

$U G=$ project urban growth

$U=$ Historical base urban growth

$C 1$ the coefficient of UG growth

$D=$ direction of urban growth

$C 2=$ the coefficient of Historical base urban growth

$P P=$ projected population growth by 2027

$C 3=$ the coefficient of the direction of urban growth

$A H=$ accelerating hindering of urban growth

$C 4=$ the coefficient of the projected population growth

The sum of the directional growth is estimated from the following equation to the eight geographical directions based on historical growth in these direction in the last 100 years.

$$
D=\sum_{x_{1} y_{1}}^{x_{n} y_{n}}(N+N E+E+S E+S+S W+W+N W)
$$

$D$ is the cumulative of the directional growth based on the historical trend of urban growth in each direction in each $(N=$ North, $N E=$ north east, $E=$ east, $S E=$ south east, $S=$ south, $S W=$ south west, $W=$ west and $N W=$ north west)i 
Table 6. Historical and projected population growth in Menofya Governorate Cities from 1907 to 2006.

\begin{tabular}{ccccccccccc}
\hline \multirow{2}{*}{ City } & \multicolumn{9}{c}{ Population Record } & \multicolumn{1}{c}{ Projected } \\
\cline { 2 - 10 } & $\mathbf{1 9 0 7}$ & $\mathbf{1 9 2 7}$ & $\mathbf{1 9 4 7}$ & $\mathbf{1 9 6 0}$ & $\mathbf{1 9 7 6}$ & $\mathbf{1 9 8 6}$ & $\mathbf{1 9 9 6}$ & $\mathbf{2 0 0 6}$ & $\mathbf{2 0 2 7}$ \\
\hline Ashmon & 13,900 & 18,504 & 23,047 & 29,095 & 39,507 & 54,450 & 68,793 & 83,931 & 122,716 \\
AlBagor & 10,038 & 11,331 & 12,283 & 15,258 & 17,993 & 26,327 & 31,291 & 41,072 & 68,033 \\
Alshohada & 14,346 & 16,733 & 17,340 & 20,687 & 25,747 & 34,653 & 41,057 & 49,447 & 70,666 \\
Berket Elsabae & 8657 & 8850 & 9491 & 12,391 & 17,473 & 24,005 & 28,917 & 33,873 & 46,064 \\
Tala & 15,018 & 18,145 & 18,665 & 23,393 & 30,277 & 38,584 & 44,010 & 49,468 & 62,351 \\
Sers Allyan & 15,453 & 17,291 & 19,973 & 21,369 & 27,017 & 36,215 & 44,267 & 52,653 & 73,600 \\
Shbien El-Kom & 30,766 & 37,488 & 52,873 & 68,579 & 102,805 & 132,209 & 156,794 & 177,112 & 225,309 \\
Qewisna & 2152 & 4893 & 8212 & 12,666 & 20,596 & 30,520 & 36,492 & 44,667 & 65,680 \\
Menouf & 22,316 & 26,078 & 31,475 & 41,914 & 55,208 & 69,673 & 77,773 & 89,262 & 116,953 \\
Total & 132,646 & 159,313 & 193,359 & 245,352 & 336,623 & 446,636 & 529,394 & 621,485 & 851,372 \\
\hline
\end{tabular}

Table 7. Coefficients for the projection of urban growth.

\begin{tabular}{|c|c|c|c|c|c|c|c|c|c|c|c|c|c|c|c|}
\hline \multirow{2}{*}{ City } & \multirow{2}{*}{$\begin{array}{c}\text { Coefficient } \\
\text { of } \\
\text { Historical } \\
\text { Base of } \\
\text { Urban } \\
\text { Growth }\end{array}$} & \multicolumn{8}{|c|}{ Coefficient of Directional Growth } & \multirow{2}{*}{$\begin{array}{c}\text { Coefficient } \\
\text { of } \\
\text { Projected } \\
\text { Population }\end{array}$} & \multicolumn{5}{|c|}{$\begin{array}{l}\text { Coefficient of Accelerating } \\
\text { /Hindering Parameters }\end{array}$} \\
\hline & & $\mathbf{N}$ & NE & $\mathbf{E}$ & SE & $\mathbf{S}$ & SW & $\mathbf{W}$ & NW & & Roads & Railways & Canals & Drainage & Total \\
\hline Ashmon & 0.145 & 0.065 & 0.09 & 0.095 & 0.075 & 0.035 & 0.04 & 0.045 & 0.055 & 0.145 & 0.08 & 0.08 & 0.025 & 0.025 & 1 \\
\hline AlBagor & 0.18 & 0.155 & 0.095 & 0.04 & 0.04 & 0.05 & 0.02 & 0.02 & 0.08 & 0.115 & 0.08 & 0.08 & 0.025 & 0.02 & 1 \\
\hline Alshohada & 0.12 & 0.075 & 0.045 & 0.065 & 0.06 & 0.055 & 0.055 & 0.07 & 0.075 & 0.105 & 0.1 & 0.1 & 0.05 & 0.025 & 1 \\
\hline $\begin{array}{l}\text { Berket } \\
\text { Elsabae }\end{array}$ & 0.195 & 0.01 & 0.055 & 0.16 & 0.19 & 0.05 & 0.01 & 0.02 & 0.005 & 0.11 & 0.075 & 0.075 & 0.025 & 0.02 & 1 \\
\hline Tala & 0.135 & 0.08 & 0.035 & 0.03 & 0.07 & 0.055 & 0.07 & 0.105 & 0.055 & 0.1 & 0.1 & 0.1 & 0.045 & 0.02 & 1 \\
\hline $\begin{array}{c}\text { Sers } \\
\text { Allyan }\end{array}$ & 0.125 & 0.045 & 0.065 & 0.07 & 0.08 & 0.075 & 0.075 & 0.055 & 0.035 & 0.095 & 0.105 & 0.105 & 0.05 & 0.02 & 1 \\
\hline $\begin{array}{l}\text { Shbien } \\
\text { El-Kom }\end{array}$ & 0.23 & 0.185 & 0.175 & 0.03 & 0.02 & 0.01 & 0.015 & 0.01 & 0.055 & 0.14 & 0.05 & 0.05 & 0.02 & 0.01 & 1 \\
\hline Qewisna & 0.19 & 0.085 & 0.085 & 0.035 & 0.025 & 0.025 & 0.03 & 0.065 & 0.15 & 0.235 & 0.04 & 0.025 & 0.005 & 0.005 & 1 \\
\hline Menouf & 0.17 & 0.1 & 0.06 & 0.05 & 0.085 & 0.11 & 0.025 & 0.02 & 0.05 & 0.11 & 0.075 & 0.075 & 0.045 & 0.025 & 1 \\
\hline
\end{tabular}

The sum of the accelerating and hindering infrastructures to the urban growth is estimated from the following equation based on the historical growth along these infrastructures in the last 100 years.

$$
A H=\sum_{x_{1} y_{1}}^{x_{n} y_{n}}(R+R a+C+D)
$$

$A H$ is the cumulative accelerating or hindering the urban growth including the infrastructures $R=$ roads, $R a=$ railways, $C=$ canals and $D=$ drainage)

Table 7 lists the coefficient matrix of all the above coefficients for each city which was applied in ArcGIS 10 package to spatially project the pixel diffusion that represent the proposed projected urban growth.

It is projected that the urban growth will be maintained in the pattern and at the same direction along the highways and railways, which act as catalysts for urban growth. The trend and magnitude of increase will vary 
from city to other based on the historical record and population growth. Shbein El-Koum, Meouf and Ashmoun are expected to be the highest cities for projected population growth and urban growth. The highways and railways maintained the linear pattern of urban growth in these cities, which are the most accelerating infrastructures for urban growth. It is followed by Sers Alyyan, Alshohada, Albagour Qewisna and Tala. The pattern of projected urban growth in these cities is circular except for Albagour due to its original linear shape. The least city in population is Berkt Elsabae, which expected its population to be only 46064 inhabitants and projected to be extended in all directions (Figure 5).

Thus, indicating that the pressure on agricultural land would further grow and areas around the highways would become prime targets for further urban growth. This would also give a picture of the pressures on the land, which the planners have to address in their future planning or amending the exiting actual plans. With an understanding of the land requirement under the current trend, the techniques of GIS and remote sensing can be applied for effective infrastructure facilities and resource utilisation.

\section{Conclusions}

Urban growth in Egypt is having an increasing impact on the agriculture land of the Nile Delta, environmental quality, and human well-being in the forthcoming decades. The urban growth in the main cities of Menofya

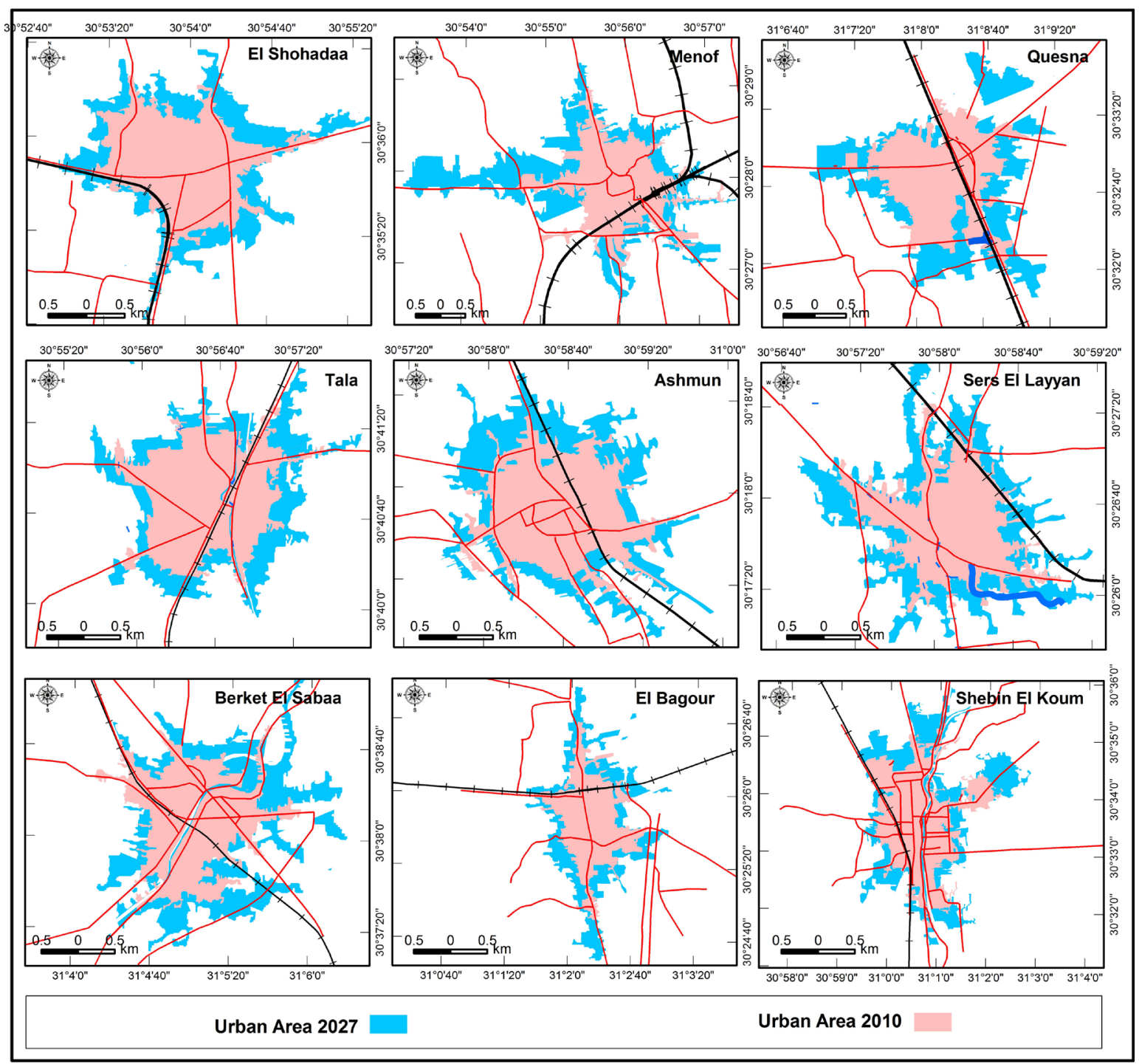

Figure 5. Projected urban growth by 2027. 
Governorate gave an indication of severe problem of urbanization. It is projected that significant amounts of the agricultural land will be transformed by urbanization.

Geographic information analysis was effective for quantifying the urban growth and determining its pattern in the Menofya Governorate in the last century from 1910 to 2010. However, it looked apparent that urban growth was a part of urbanization processes in the governorate to accommodate the population growth. It was influenced by the economical and international situation. The highest stage of urban growth was in the second half of the 20th century after the World War II and the Egyptian Revolution in 1952. The economical growth in the 1970s and 1980s has maintained this large urban growth. Most of the urban growth was in linear pattern aligned with the highways and railways infrastructures. Such urban growth was under the pressure of the population increase. The population of these cities was unprecedentedly increased in the last century by nearly 6 times. The average percent of population increase was $500 \%$ with the maximum of nearly $2000 \%$ in Qewisna and the minimum of $230 \%$ in Tala. Indeed, such over increase has put pressure on the urban growth for housing and services.

The urban growth of Menofya Governorate cities was 12 times in the last century. The increase of the built-up area was classified into 5 stages with the highest rate of increase in the third stage from 1950 to 1972, which increased by $124 \%$. The urban growth continued in increase up to the 2010 getting outside the legal urbanized border. The majority of the pattern was linear with little examples of circular such as Alshohada and radial such as Tala. Most of the growth of built-up areas was along the highways and railways, particularly in the north direction. The north driven direction is driven by the wind direction and health issues.

Ultimately, an understanding of the urban growth and growth in the cities of Menofya Governorate are gained and enabled to project the future extension that may put extra pressure on the services and human needs. Urbanization in Menofya Governorate is projected to be increased by $3.1 \%$ in 2027 . These growth projections assumed that the patterns of urban growth that occurred between 1910 and 2010 would continue to occur over the next 13 years. These projections reveal areas where agriculture resources are most likely to be influenced by expanding urbanization. The projections given in this research are based on the local average urban growth within each city and they assume that population will increase at the same rate.

In summary, it is well recognized that urban growth in the last century is the main driver of agricultural land degradation of the Nile Delta fertile land that secures food for the community. Therefore, there is a need for more improved coordination between decision makers liable for urban development and planners to control the urban growth that erodes the agricultural fertile land. It is important that planners and decision makers consider vertical urban development for optimal use of land. There is also a need to strengthen the counties and institutions that are responsible for land use planning with modern technology of GIS to enable professional geographical analysis.

\section{References}

[1] Nechyba, T.J. and Walsh, R.P. (2004) Urban Sprawl. Journal of Economic Perspectives, 18, 177-200. http://dx.doi.org/10.1257/0895330042632681

[2] Torrens, P.M. and Alberti, M. (2000) Measuring Sprawl. Working Paper No. 27, Centre for Advanced Spatial Analysis, University College London, London.

[3] Zhang, T. (2001) Community Features and Urban Sprawl: The Case of the Chicago Metropolitan Region. Land Use Policy, 18, 221-232. http://dx.doi.org/10.1016/S0264-8377(01)00018-7

[4] Lata, K.M., Sankar, R.C.H., Krishna, P.V., Badrinath, K.V.S. and Raghavaswamy, V. (2001) Measuring Urban Sprawl: A Case Study of Hyderabad. GIS Development, 5, 26-29.

[5] Theobald, D.M. (2001) Quantifying Urban and Rural Sprawl Using the Sprawl Index. Proceedings of the Association of American Geographers, New York, 2 March 2001, 544-564.

[6] Haack, B. and Rafter, A. (2006) Urban Growth Analysis and Modeling in the Kathmandu Valley, Nepal. Habitat International, 30, 1056-1065. http://dx.doi.org/10.1016/j.habitatint.2005.12.001

[7] Coulter, L., Stow, D., Kiracofe, B. and Langevin, C. (1999) Deriving Current Land-Use information for Metropolitan Transportation Planning through Integration of Remotely Sensed Data and GIS. Photogrammetric Engineering and Remote Sensing, 65, 1293-1300.

[8] Seong, T.K. (1994) Applications of Remote Sensing and Geographical Information Systems for Urban Planning in Developing Countries: Potential and Pitfalls. United Nations Centre for Regional Development, Nagoya.

[9] Barnes K.B., Morgan, J.M., Roberge, M.C. and Lowe, S. (2001) Sprawl Development: Its Patterns, Consequences, and 
Measurement. Towson University, Towson. http://chesapeake.towson.edu/landscape/urbansprawl/

[10] Epstein, J., Payne, K. and Kramer, E. (2002) Techniques for Mapping Suburban Sprawl. Photogrammetric Engineering and Remote Sensing, 63, 913-918.

[11] Civco, D.L., Hurd, J.D., Wilson, E.H., Arnold, C.L. and Prisloe, M. (2002) Quantifying and Describing Urbanizing Landscapes in the Northeast United States. Photogrammetric Engineering and Remote Sensing, 68, 1083-1090.

[12] Claramunt, C. and Jiang, B. (2001) An Integrated Representation of Spatial and Temporal Relationships between Evolving Regions. Journal of Geographic Systems, 3, 411-428. http://dx.doi.org/10.1007/s101090100066

[13] Lo, C.P. and Yang, X. (2002) Drivers of Land-Use/Land-Cover Changes and Dynamic Modelling for the Atlanta, Georgia Metropolitan Area. Photogrammetric Engineering and Remote Sensing, 68, 1062-1073.

Murphy, D.L. (1985) Estimating Neighborhood Variability with a Binary Comparison Matrix. Photogrammetric Engineering and Remote Sensing, 51, 667-674.

[14] Longley, P., Higgs, G. and Martin, D. (1994) The Predictive Use of GIS to Model Property Valuations. International Journal of Geographical Information Science, 8, 217-235. http://dx.doi.org/10.1080/02693799408901995

[15] Clarke, K.C. and Gaydos, L.J. (1998) Loose-Coupling a Cellular Automaton Model and GIS: Long-Term Urban Growth Prediction for San Francisco and Washington/Baltimore. International Journal of Geographical Information Science, 12, 699-714. http://dx.doi.org/10.1080/136588198241617

[16] Li, X. and Yehm A.G.O. (2000) Modelling Sustainable Urban Development by the Integration of Constrained Cellular Automata and GIS. International Journal of Geographical Information Science, 14, 131-152. http://dx.doi.org/10.1080/136588100240886

[17] Li, X. and Yeh, A.G.O. (2002) Neural-Network-Based Cellular Automata for Simulating Multiple Land Use Changes Using GIS. International Journal of Geographical Information Science, 16, 323-243. http://dx.doi.org/10.1080/13658810210137004

[18] Yang, X. and Lo, C.P. (2003) Modeling Urban Growth and Landscape Changes in the Atlanta Metropolitan Area. International Journal of Geographical Information Science, 17, 463-488. http://dx.doi.org/10.1080/1365881031000086965 